\title{
Début et fin dans la narration balzacienne. Textes réunis par Fancesco Fiorentino
}

\section{Marco Stupazzoni}

\section{Q OpenEdition}

1 Journals

\section{Edizione digitale}

URL: https://journals.openedition.org/studifrancesi/39608

DOI: 10.4000/studifrancesi.39608

ISSN: 2421-5856

\section{Editore}

Rosenberg \& Sellier

\section{Edizione cartacea}

Data di pubblicazione: 1 décembre 2004

Paginazione: 392-393

ISSN: 0039-2944

\section{Notizia bibliografica digitale}

Marco Stupazzoni, «Début et fin dans la narration balzacienne. Textes réunis par Fancesco Fiorentino», Studi Francesi [Online], 143 (XLVIII | II) | 2004, online dal 30 novembre 2015, consultato il 19 mai 2021. URL: http://journals.openedition.org/studifrancesi/39608; DOI: https://doi.org/10.4000/studifrancesi. 39608

Questo documento è stato generato automaticamente il 19 mai 2021.

\section{(c) (1)}

Studi Francesi è distribuita con Licenza Creative Commons Attribuzione - Non commerciale - Non opere derivate 4.0 Internazionale. 


\title{
Début et fin dans la narration balzacienne. Textes réunis par Fancesco Fiorentino
}

\author{
Marco Stupazzoni
}

\section{NOTIZIA}

AA. VV., Début et fin dans la narration balzacienne. Textes réunis par Fancesco FIORENTINO, Taranto, Lisi, 2002 («Palazzo Ateneo», 1), pp. 122.

1 Gli studî raccolti in questo agile volume costituiscono gli atti del Convegno tenutosi all'Università di Bari il 26 febbraio 2000 nell'ambito delle celebrazioni del bicentenario della nascita di Balzac.

2 Curata da F. Fiorentino, questa pubblicazione merita, a nostro avviso, un'attenzione particolare per la ricchezza e la profondità dei singoli interventi su vari aspetti della narrazione balzachiana, nel contesto più generale di un confronto tra prospettive $\mathrm{e}$ metodologie critiche diverse quanto mai produttivo e sempre auspicabile.

3 Roland Chollet ("La Comédie humaine" a-t-elle un début et une fin?, pp. 9-32) riflette con acume sulla costante e tenace ossessione balzachiana di fornire al lettore gli strumenti per percepire la leggibilità specifica del monumento-Comédie humaine. Siamo di fronte a una questione cruciale della poetica letteraria di Balzac: le variazioni presenti nella rappresentazione mentale che lo scrittore si fece della sua opera perennemente provvisoria e in divenire riguardano il «leitmotiv du monument et de sa lecture, le problème irrésolu, informulé, omniprésent cependant, de la narrativité en conflit avec la monumentalité» (p. 27). L'A. esamina le ambiguità della metafora monumentale applicata alla Comédie humaine, attraverso cui Balzac seppe decretare il suo atto di nascita come autore letterario, assicurandosi il privilegio di «constituer son oeuvre romanesque en propriété unique inaliénable» (p.32) e fornendo ai lettori la libertà di 
percorrerla, di esplorarla e di abitarla in uno spazio senza un inizio e senza una fine prestabiliti in maniera assoluta.

4 Pier Vincenzo Mengaldo (Deux chapitres sur "Le cousin Pons", pp. 33-59) focalizza la sua attenzione sui primi due capitoli del romanzo balzachiano fornendo una penetrante analisi delle tematiche narrative e dei procedimenti analogici che informano il discorso romanzesco dello scrittore. Nella parte iniziale del suo intervento, Mengaldo si sofferma, più particolarmente, su uno dei tratti polivalenti della scrittura balzachiana, di cui Le cousin Pons è eccezionalmente ricco: ci riferiamo al sistema dei «patronymes parlants» (p. 33) dietro cui si celano non solo il destino dei personaggi, ma due tra gli aspetti fondamentali della «mens balzacienne, l'ironie et l'analogie» (p. 35). Nel ritratto di Pons che Balzac offre nei primi due capitoli del romanzo - ritratto inversamente speculare a quello di Lucien in Splendeurs et misères des courtisanes -, l'A. scorge, da un lato «l'annonce, la prolepse, la synthèse de ce qui sera raconté et signifié dans ce roman»; dall'altro, «les indices de la manière générale d'écrire de son auteur» (p. 40). La pluralità dei punti di vista che ci informano sul personaggio «relève du procédé typique de Balzac de l'avalanche, de l'approximation et de l'expansion» (pp. 49-50): è, in particolare, il carattere funzionale dell'espansione analogica che invade potentemente il tessuto narrativo dell'opera attraverso gli strumenti della similitudine e della digressione.

5 André LORANT (L'ouverture et la clôture dans la «trilogie passionnelle» des «Premiers romans» (1822-1825), pp. 61-79) esamina la correlazione tra l'«ouverture» e la «clôture», tra le prime e le ultime pagine delle opere che formano la «trilogie passionnelle» dei Premiers romans: Le Vicaire des Ardennes, Le Centenaire e Annette et le criminel, romanzi pubblicati tra il 1822 e il 1825. Si tratta, osserva l'A., di una "expérimentation créatrice» (p. 79) assunta e sviluppata da Balzac all'interno di una logica narrativa che consente al lettore di seguire l'evoluzione degli eventi e, soprattutto, dei personaggi nel corso dell'opera. Se la creazione di figure poco credibili «a permis à Balzac de mettre en oeuvre, dans le cadre de romans, ses fantasmes les plus personnels» (Ibid.), la ricerca di una visione unitaria del mondo consente allo scrittore di sviluppare alcuni temi centrali della poetica romantica, quali, ad esempio, il sogno, la natura, i misteri della scienza, il fascino della religione e delle sue manifestazioni mistiche.

6 Mariolina BongIovanNi BeRTINI (Désir mimétique et mélodrame: une lecture de "Pierrette" d'Honoré de Balzac, pp. 81-98) attribuisce a Pierrette un'importanza fondamentale all'interno del discorso letterario balzachiano. In questo romanzo, dove sono denunciati «les dégâts produits, dans un contexte social déterminé, par le désir médiat et par la rivalité mimétique débouchant à la fin sur le sacrifice, provisoirement pacificateur, d'une victime innocente» (p. 83), i feroci tratti del realismo di Balzac si sovrappongono alle soavi tonalità idilliache che connotano la figura angelica di Pierrette, in una sorta di progressione estetica che trova la sua più alta ed intensa realizzazione, psicologica e morale, nelle forme del melodramma.

7 Francesco FIORENTINO ( $\mathrm{Au}$ commencement, la maison. Un incipit balzacien, pp. 99-110) analizza le tre diverse versioni dell'incipit de La Maison du chat-qui-pelote (la cui prima edizione risale al 1830 con il titolo di Gloire et malheur), il racconto che inaugura il grande ciclo della Comédie humaine. Interrogarsi sulle «différentes options de débuts signifie, donc, - per Fiorentino - pénétrer à l'intérieur du laboratoire de Balzac, au moment même de sa formation» (p. 99). Rispetto alla prima versione, le due versioni successive (compresa quella definitiva) «représentent un saut de qualité décisif de l'art 
du récit balzacien» (p. 101): anzitutto, scrive bene l'A., esse costituiscono un momento importante nel processo di autonomia del romanzo rispetto ai protocolli del sapere (storico, filosofico, scientifico); in secondo luogo, esse fissano «une modalité de début pour laquelle le romancier aura une prédilection»: la descrizione di un edificio costituirà, infatti, «la modalité balzacienne de commencement la plus fréquente: une sorte de label imprimé dans l'incipit de ses oeuvres» (p. 102). È il rapporto dialettico tra esterno e interno nella descrizione della 'maison' a costituire il motore dell'immaginario romanzesco balzachiano: da questo contrasto, ridefinibile secondo la formula di E. Bloch come la "contemporanéité du non contemporain", si riflette non solo una caratteristica capitale della modernità, ma anche uno dei principî dinamici più incisivi dell'arte narrativa balzachiana.

8 Max ANDRÉOLI (Le 'renversement' dans le récit balzacien, pp. 111-122) pone la sua attenzione su una modalità particolare di restituzione narrativa dell'incipit romanzesco, il «renversement ou retournement» (p. 112), attraverso cui Balzac esprime, sotto la prospettiva filosofica e metafisica, il carattere duplice e contraddittorio dell'uomo e del mondo. L'analisi di Andréoli verte, in modo particolare, su tre testi: La Maison du chatqui-pelote, Eugénie Grandet e Illusion perdues. A suo giudizio, nel procedimento del 'renversement', grazie al quale «l'inversion finale reflète l'image complète ou quasi symétrique du début», si determina la circolarità di una figura narrativa plurale e significativa: «le début et la fin, puntualizza l'A., ne marquent pas nécessairement un contact manqué entre des sphères; néanmoins ce modèle, revêtant diverses formes, convient à maints romans de La Comédie humaine» (p. 114). 